\title{
Fitorremediação dos herbicidas 2,4-diclorofenoxiacético e propanil em solo cultivado por erva cidreira (Melissa officinalis)
}

\author{
Phytoremediation of 2,4-dichlorophenoxyacetic and propanil herbicides in soil \\ cultivated by herb lemon balm (Melissa officinalis)
}

\author{
Bruna Ramborger Piaia, Maria Luisa Candido Zago, Elton Luís Gasparoto Denardin \\ e Rafael Roehrs \\ Universidade Federal do Pampa, RS, Brasil \\ bruna-pr@hotmail.com; maluzago@hotmail.com; edenardin@unipampa.edu.br; rafael.roehrs@unipampa.edu.br
}

\section{Resumo}

O uso frequente ou incorreto de pesticidas pode acarretar em contaminações no solo, águas e alimentos. Para evitar tais contaminações o presente estudo avaliou o potencial de fitorremediação da Melissa officinalis em solo contendo uma mistura dos pesticidas comerciais Aminol e Herbipropanin (2,4-D e propanil). Amostras de solo (250,0 g) foram fortificadas com três concentrações da mistura dos pesticidas comerciais $\left(0,1612 \mathrm{~g} \mathrm{Kg}^{-1}+0,072 \mathrm{~g} \mathrm{Kg}{ }^{-1}\right.$; $0,0806 \mathrm{~g} \mathrm{Kg}^{-1}+0,0403 \mathrm{~g} \mathrm{Kg}^{-1} ; 0,036 \mathrm{~g} \mathrm{Kg}^{-1}+0,018 \mathrm{~g} \mathrm{Kg}^{-1}$, de Aminol e de Herbipropanin respectivamente) onde foram plantadas as mudas. Coletas sucessivas desse solo $(10,0 \mathrm{~g})$ foram realizadas para proceder a extração destes compostos com solventes orgânicos (metanol/acetato de etila 50:50 v/v) para serem analisadas em cromatografia líquida de alta eficiência com arranjo de diodos a fim de avaliar se havia diminuição dos compostos pela utilização da planta. Os resultados demonstraram que houve uma diminuição nos compostos cultivados com a planta durante 20 dias de cultivo. Esse estudo mostrou que o cultivo de Melissa officinalis pode ser uma estratégia rápida, eficaz e de baixo custo para a fitorremediação de solos contaminados pelos herbicidas 2,4-D e propanil e, ainda, promissora na remediação do metabólito 3,4-DCA.

Palavras-chave: Fitorremediação; Melissa officinalis; 2,4-D; Propanil.

\section{Abstract}

Frequent or misuse of pesticides can result in contamination of the soil, water and food. To avoid such contamination the present study evaluated the potential of Melissa officinalis in soil phytoremediation containing a mixture of commercial pesticides Aminol and Herbipropanin (2,4-D and propanil). Soil samples (250.0 g) were spiked with three concentrations of the mixture of the commercial pesticides $\left(0.1612 \mathrm{~g} \mathrm{~kg}^{-1}+0.072 \mathrm{~g} \mathrm{~kg}^{-1} ; 0.0806 \mathrm{~g} \mathrm{~kg}^{-1}+0.0403 \mathrm{~g} \mathrm{~kg}^{-1}\right.$; $0.036 \mathrm{~g} \mathrm{~kg}^{-1}+0.018 \mathrm{~g} \mathrm{~kg}^{-1}$, of Aminol and Herbipropanin respectively) where the seedlings were planted. Successive samplings that soil $(10.0 \mathrm{~g})$ were conducted to carry out the extraction of these compounds with organic solvents (methanol / ethyl acetate 50:50 v/v) to be analyzed by high-performance liquid chromatography with diode array to assessing whether the compounds had decreased by the use of the plant. The results showed a decrease in the plant cultivated with compounds for 20 days of cultivation. This study showed that Melissa officinalis cultivation can be a fast, effective and low-cost strategy for phytoremediation of soils contaminated by 2,4-D herbicides and propanil, and also promising in the remediation of the metabolite 3,4-DCA.

Keywords: Phytoremediation, Melissa officinalis, 2,4-D, Propanil. 


\section{Introdução}

O uso de diferentes classes de pesticidas para o controle de pragas proporcionou tanto a diminuição do índice de doenças para os homens e animais como também, aumentou a produção agrícola. Quando são aplicados no ambiente e atingem a superfície do solo, eles podem passar por processos de retenção (adsorção, absorção), transformação (decomposição, degradação) e transporte (deriva, volatização, lixiviação, escoamento superficial) os quais determinam seu destino, persistência e eficiência agronômica. Dessa forma, seu uso frequente ou incorreto pode acarretar em contaminações não apenas no solo, mas também, na atmosfera, alimentos, águas superficiais e subterrâneas. Consequentemente podem ocasionar intoxicações nos organismos presentes nessas áreas, inclusive nos humanos (tanto em contato direto na aplicação, quanto indireto por meio de organismos intoxicados) (SPADOTTO, 2004).

Os pesticidas 2,4-D e propanil são vastamente utilizados na produção de arroz que possui uma grande área de cultivo na região da Fronteira Oeste do Rio Grande do Sul. Na cidade de Uruguaiana, onde o presente estudo foi conduzido, esse cultivo é o predominante pelos seguintes fatores: condições climáticas favoráveis, elevado nível tecnológico empregado, uso intenso dos insumos agrícolas e pela geomorfologia da região que possibilita a construção de reservatórios para acúmulo de água (SILVA et al., 2007). Dessa forma, a utilização freqüente destes compostos é muito comum, o que os tornam nosso objeto de estudo.

Uma alternativa para extrair contaminantes do solo é a fitorremediação, técnica onde a planta armazena-os para tratamento subsequente, quando necessário, ou mesmo metaboliza-os, podendo transformá-los em produtos menos tóxicos ou mesmo inócuos (MADALÃO, 2013). Nesse sentido, o estudo com plantas medicinais, nesse caso com a Melissa officinalis, nos permite analisar a possível remediação dos compostos pela mesma, como também, dar um destino a ela, como forma de chá de suas folhas (na ausência dos pesticidas na planta).

A erva cidreira (Melissa officinalis) é uma espécie aromática de origem europeia e largo emprego medicinal nos quatro cantos do planeta. Ela se espalhou pelo mundo devido principalmente a suas qualidades funcionais (BLANCO, 2007). Pela sua alta adaptação em no território brasileiro, essa planta foi eleita como possível remediadora para estes pesticidas.

Com o objetivo de analisar a possível degradação desses compostos químicos (2,4-D e propanil) com o uso de plantas, este trabalho tem como proposta analisar a possível fitorremediação das mudas de Melissa officinalis para a descontaminação do solo com os pesticidas comerciais Aminol e Herbipropanin (2,4-D e propanil) por meio de análises de extração consecutivas destes pesticidas do solo em um período de 20 dias.

\section{Material e método}

\section{Padrões analíticos, reagentes e equipamentos}

Para a construção da curva analítica foram utilizados padrões de 2,4-D e propanil os quais foram adquiridos da Sigma Aldrich (Steinhein, Alemanha) e as soluções analíticas de estoque dos mesmos foram preparadas através da pesagem de $10,0 \mathrm{mg}$ de cada pesticida dissolvendo-o em $10 \mathrm{~mL}$ de acetonitrila (grau cromatográfico obtido da J.T. Baker, Holanda). A partir desta solução $\left(1.000,0 \mathrm{mg} \mathrm{L}^{-1}\right)$, foi preparada outra solução padrão de trabalho de $100 \mathrm{mg} \mathrm{L}^{-1}$ para então realizar diluições sucessivas e assim obter as seguintes concentrações: 0,$5 ; 1,0 ; 2,5 ; 5,0$ e $10,0 \mathrm{mg} \mathrm{L}^{-1} \mathrm{em}$ acetonitrila as quais foram utilizadas para a construção da curva analítica. As soluções foram mantidas sob refrigeração.

Os pesticidas comerciais foram obtidos da empresa ADAMA (Brasil). O solo e as plantas foram adquiridos do comércio local. Os solventes utilizados para a extração (solução extratora) dos pesticidas do solo foi acetato de etila grau analítico (99,5\% de pureza) e o metanol grau analítico, os quais foram obtido da Neon (São Paulo, Brasil). O agitador orbital, também utilizado para extração, foi adquirido da Tecnal (São Paulo, Brasil), os cartuchos de extração em fase sólida foram do tipo Strata-X (poros de $55 \mu \mathrm{m}$ em $500 \mathrm{mg}$, Phenomenex) e rotaevaporador à vácuo com refrigerador de líquido (BUCHI, Switzerland). O ácido fosfórico (pureza de $85 \%$ ) para acidificar a solução extratora e a fase móvel, foi adquirido da Fluka-Sigma Aldrich (Steinhein, Alemanha). A água de alta pureza foi utilizada para o condicionamento dos cartuchos para extração e também como solvente da fase móvel a partir do sistema Milli-Q da Millipore (Milford, MA, EUA). O volume ressuspendido dos pesticidas extraídos do solo foram filtrados através de filtros de seringa de membrana de PTFE $(0,22 \mu \mathrm{m})$ para posteriormente ser injetado no cromatógrafo. Para a fase móvel, utilizou-se acetonitrila e metanol grau HPLC da J.T. Baker (EUA).

Para a leitura das análises foi utilizado cromatógrafo a líquido modelo Young Lin (YL 9100, Coreia) equipado com bomba quaternária, amostrador automático e detector por arranjo de diodos (DAD). A coluna de guarda - Sistema Analítico Cartucho Guarda (KJO-4282) (Phenomenex), uma coluna analítica - coluna C18 (Sinergy Fusion RP, $250 \mathrm{~mm} \times$ 4,6 mm x $4 \mu \mathrm{m})$ da Phenomenex. 


\section{Composição da amostra de solo}

O solo era do tipo para jardinagem e continha as seguintes características:

- Especificações: terra vermelha, terra preta e rocha calcária moída.

- Capacidade de retenção de água (p/v): $40 \%$

- Condutividade elétrica: $30-40 \mu \mathrm{S} / \mathrm{cm}$

- Densidade à $20^{\circ} \mathrm{C}$ (base seca): $950,9 \mathrm{Kg} / \mathrm{m}^{3}$

- Umidade máxima $(\mathrm{p} / \mathrm{v}): 40 \%$

- $\mathrm{pH}$ a $20^{\circ} \mathrm{C}: 6,0$

\section{Avaliação da sensibilidade da planta aos pesticidas}

Foi avaliada a resposta das plantas através da sensibilidade em concentrações crescentes dos pesticidas a fim de obter as concentrações não letais destes compostos para o estudo. A análise da resposta das plantas foi de acordo com a coloração folhar e caulinar, secura ou morte das plantas.

Para isso, as mudas ficaram inicialmente em período de adaptação durante seis dias na estufa em temperatura ambiente e com suas variações. No sétimo dia, 250 gramas de solo foram fortificados com a mistura dos pesticidas comerciais (Aminol e Herbipropanin - 2,4-D e propanil) e colocados em potes de jardinagem nas concentrações determinadas para a avaliação da sensibilidade pela planta. Para a aplicação de cada uma dessas concentrações no solo, foi utilizada uma quantidade de água (aproximadamente $100 \mathrm{~mL}$ ) para melhor homogeneizar ambos os pesticidas no solo. As concentrações avaliadas foram: 0,3224 $\mathrm{g} \mathrm{Kg}^{-1}+0,144 \mathrm{~g} \mathrm{Kg}^{-1} ; 0,1612 \mathrm{~g} \mathrm{Kg}^{-1}+$ 0,072 $\mathrm{g} \mathrm{Kg}^{-1} ; 0,0806 \mathrm{~g} \mathrm{Kg}^{-1}+0,036 \mathrm{~g} \mathrm{Kg}^{-1}$ de solo de Aminol e de Herbipropanin respectivamente. Essas concentrações são 267 vezes superiores ao recomendado para aplicação do composto 2,4-D e 40 vezes superior para o propanil no solo. Essas concentrações relativamente altas em comparação ao aplicado foram utilizadas para verificar a concentração máxima suportada pela planta. Assim, em caso de um desastre ecológico este método pode ser utilizado, como no caso de Mariana- MG (novembro de 2015).

\section{Tratamento para fitorremediação}

Após a avaliação da sensibilidade da planta aos pesticidas, o trabalho foi composto pelas seguintes grupos: Tratamento: composto por uma muda da planta por pote que foi plantada no solo fortificado com a mistura dos pesticidas; Controle: composto apenas pelo solo fortificado, a fim de analisar a autodegradação dos pesticidas pelas condições ambientais; Branco: composto por uma muda da planta por pote que foi plantada no solo sem a fortificação dos pesticidas. A etapa anterior (sensibilidade) foi realizada em duplicata, enquanto que o experimento da fitorremediação foi realizado em triplicata. Nos dois testes houve o ciclo claro/escuro de acordo com a luz solar e à temperatura entre $10-24^{\circ} \mathrm{C}$.

\section{Extração dos pesticidas da amostra de solo}

O método para a extração dos pesticidas da amostra de solo foi baseado no trabalho de Niell et al. (2010) com modificações, resumidamente: foi coletado $10,0 \mathrm{~g}$ de solo já fortificado com a maior concentração dos pesticidas comerciais e transferidos para um frasco de erlenmeyer. Posteriormente, foi realizada uma extração sólido-líquido da seguinte maneira: Nos $10,0 \mathrm{~g}$ de solo foram adicionados $20 \mathrm{~mL}$ da solução metanol e acetato de etila $(50: 50 \mathrm{v} / \mathrm{v})$ e o frasco foi submetido à um agitador orbital hortizontal por 15 minutos. Os extratos obtidos foram filtrados em papel filtro qualitativo ( $150 \mathrm{~mm}$ de tamanho de poro) e lavados com o mesmo solvente de extração $(2 \times 10 \mathrm{ml})$, sendo posteriormente evaporado com o evaporador rotativo $\left(40^{\circ} \mathrm{C}\right)$. Após a evaporação, os pesticidas foram ressuspendidos em $1,5 \mathrm{ml}$ de acetonitrila. A solução foi filtrada com filtro de $0,22 \mu \mathrm{m}$ diretamente para um vial e em seguida analisada por Cromatografia Líquida de Alta Eficiência por Arranjo de Diodos (HPLC-DAD).

\section{Condições cromatográficas}

A fase móvel utilizada foi de acordo com o trabalho de Rosa (2013), onde foi aplicada acetonitrila/metanol/água (pH 3), numa proporção de 27:27:46, com taxa de fluxo de $0,9 \mathrm{ml} / \mathrm{min}$ até 20 minutos e 30:30:40 com taxa de fluxo de 1,2 $\mathrm{mL} / \mathrm{min}$ no tempo de 20-35 min. $\mathrm{O}$ pH da água da fase móvel foi ajustado para $\mathrm{pH} 3 \mathrm{com}$ solução aquosa de ácido fosfórico (1:1, v/v). O volume de injeção foi de $20 \mu \mathrm{L}$, e comprimentos de onda de detecção foram de $220 \mathrm{~nm}$ para 2,4-D e $254 \mathrm{~nm}$ para o propanil. As análises foram realizadas à temperatura ambiente. 


\section{Resultados e discussão}

\section{Sensibilidades das mudas de $M$. officinalis aos pesticidas}

Para dar início ao estudo, foi necessário avaliar as concentrações dos pesticidas que não fossem letais ou que não prejudicassem o crescimento e desenvolvimento da planta. Como estes compostos são herbicidas, são capazes de causar inibição de transporte de elétrons na fotossíntese em plantas de folhas largas (propanil) (TOMLIN, 2007), ou provocar desde o crescimento anormal de tecidos, obstrução do floema, até morte do sistema radicular (2,4-D) (SBANO et al., 2013). Assim, através dessa análise, seria possível analisar se a planta de $M$. officinalis seria tolerante aos pesticidas e quais concentrações seriam utilizadas para o desenvolvimento do processo de fitorremediação.

Com a adição das três concentrações decrescentes da solução mista comercial dos herbicidas $\left(0,3224 \mathrm{~g} \mathrm{Kg}^{-1}+0,144 \mathrm{~g} \mathrm{Kg}^{-1}\right.$; 0,1612 $\mathrm{g} \mathrm{Kg}^{-1}+0,072 \mathrm{~g} \mathrm{Kg}^{-1} ; 0,0806 \mathrm{~g} \mathrm{Kg}^{-1}+$ 0,036 $\mathrm{g} \mathrm{Kg}^{-1}$ de Aminol e de Herbipropanin respectivamente), conforme a metodologia, foi possível obter visualmente uma resposta não prejudicial para as plantas nas duas concentrações mais baixas $(0,1612 \mathrm{~g}$ $\mathrm{Kg}^{-1}+$ 0,072 $\mathrm{g} \mathrm{Kg}^{-1} ; 0,0806 \mathrm{~g} \mathrm{Kg}^{-1}+0,036 \mathrm{~g} \mathrm{Kg}^{-1}$ de Aminol e de Herbipropanin respectivamente). Porém, já no terceiro e quarto dia da análise da sensibilidade da planta foi possível observar que a maior concentração desta solução mista evidenciou danos folhares e em parte do seu caule, deixando-as murchas e posteriormente secas. Dessa forma, essa maior concentração tornou-se inviável para o estudo conforme mostra a Figura 1.

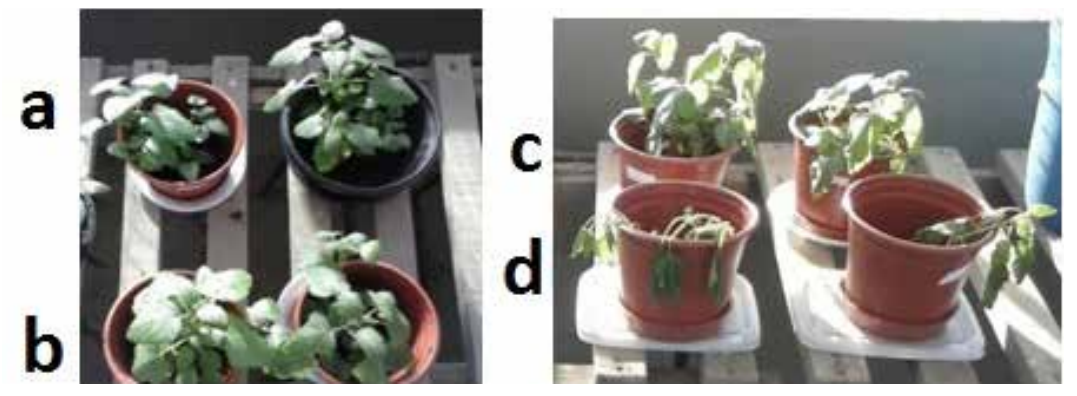

Figura 1 - Foto do terceiro dia das mudas de Melissa officinalis expostas à mistura dos herbicidas comercias nas três concentrações crescentes juntamente a uma amostra branco, onde a planta não foi exposta. Na figura, a) representam a amostra branco; b) mudas expostas à mistura dos herbicidas na concentração de $0,0806 \mathrm{~g} \mathrm{Kg}^{-1}+0,036 \mathrm{~g} \mathrm{Kg}^{-1}$ de Aminol e Herbipropanin respectivamente; c) mudas expostas à mistura dos herbicidas na concentração de 0,1612 $\mathrm{g} \mathrm{Kg}^{-1}+0,072 \mathrm{~g} \mathrm{Kg}^{-1}$ de Aminol e Herbipropanin respectivamente; d) mudas expostas à mistura dos herbicidas na concentração de 0,3224 $\mathrm{g} \mathrm{Kg}^{-1}+0,144 \mathrm{~g} \mathrm{Kg}^{-1}$ de Aminol e Herbipropanin respectivamente. A figura mostra que as mudas expostas à maior concentração (d) foram as que sofreram injúrias.

Uma nova concentração mais baixa foi preparada, mantendo-se ainda as duas concentrações anteriores que não prejudicaram a planta. Sendo assim a nova concentração continha: $0,0403 \mathrm{~g} \mathrm{Kg}^{-1}+0,018 \mathrm{~g} \mathrm{Kg}^{-1}$ de Aminol e de Herbipropanin respectivamente. Como esperado, foi possível observar na Figura 2 que essas concentrações não prejudicaram o crescimento das plantas durante o novo período de sensibilidade, tornando-as usuais para o seguimento do estudo. A figura mostra que as mudas não sofreram injúrias (não foram sensíveis) em todas as concentrações testadas.

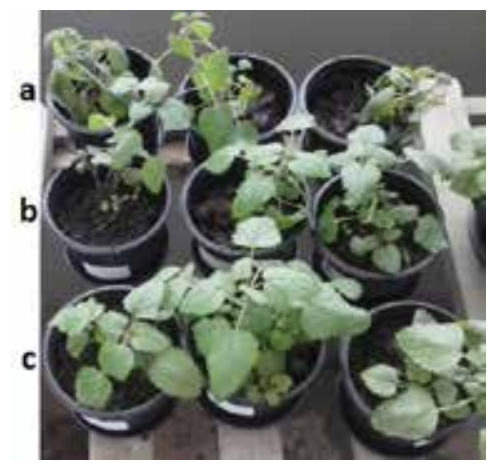

Figura 2 - Foto do terceiro dia das mudas de Melissa officinalis expostas à mistura dos herbicidas comercias nas três novas concentrações. Na figura: a) mudas expostas à mistura dos herbicidas na concentração de $0,1612 \mathrm{~g} \mathrm{Kg}^{-1}+0,072 \mathrm{~g} \mathrm{Kg}^{-1}$ de Aminol e de Herbipropanin respectivamente; b) mudas expostas à mistura dos herbicidas na concentração de 0,0806 $\mathrm{g} \mathrm{Kg}^{-1}+0,036 \mathrm{~g} \mathrm{Kg}{ }^{-1}$ de Aminol e de Herbipropanin respectivamente; c) mudas expostas à mistura dos herbicidas na concentração de $0,0403 \mathrm{~g} \mathrm{Kg}^{-1}+0,018 \mathrm{~g} \mathrm{Kg}^{-1} \mathrm{de} \mathrm{Aminol}$ e de Herbipropanin respectivamente. 


\section{Condições cromatográficas e método de extração}

Para a construção da curva cromatográfica obtivemos os seguintes parâmetros cromatográficos: equação da reta do composto 2,4-D de y $=41,60 x-21,90$ e $\mathrm{r}^{2}=0,996$ com uma faixa linear de 0,5 a $10 \mathrm{mg} \mathrm{L}^{-1}$. Já para o composto propanil, a equação da reta obtida foi: $\mathrm{y}=64,76 \mathrm{x}-27,30 \mathrm{e}^{2}=0,995 \mathrm{com}$ uma faixa linear de 0,5 a $10 \mathrm{mg} \mathrm{L}^{-1}$. Esses dados da curva analítica estão de acordo com a literatura, pois, segundo Harris (2012) um $\mathrm{r}^{2}$ maior que 0,995 ou 0,999 é considerado como evidência de um ajuste ideal dos dados para a linha de regressão. Para a ANVISA (BRASIL, 2003) recomenda-se um coeficiente de correlação igual ou superior a 0,99 e o INMETRO um valor acima de 0,90 (RIBANI, 2004).

O método de extração utilizado para a avaliação dos pesticidas no solo mostrou ser eficiente uma vez que foram extraídos ambos os pesticidas de maneira eficaz e seletiva (Figura 3). O cromatograma da Figura 3 mostra também que a extração tanto para a amostra controle, quanto a amostra do tratamento com a planta apresentaram a mesma concentração inicial dos pesticidas. Isso evidencia a eficiência na extração das concentrações as quais foram utilizadas no estudo.

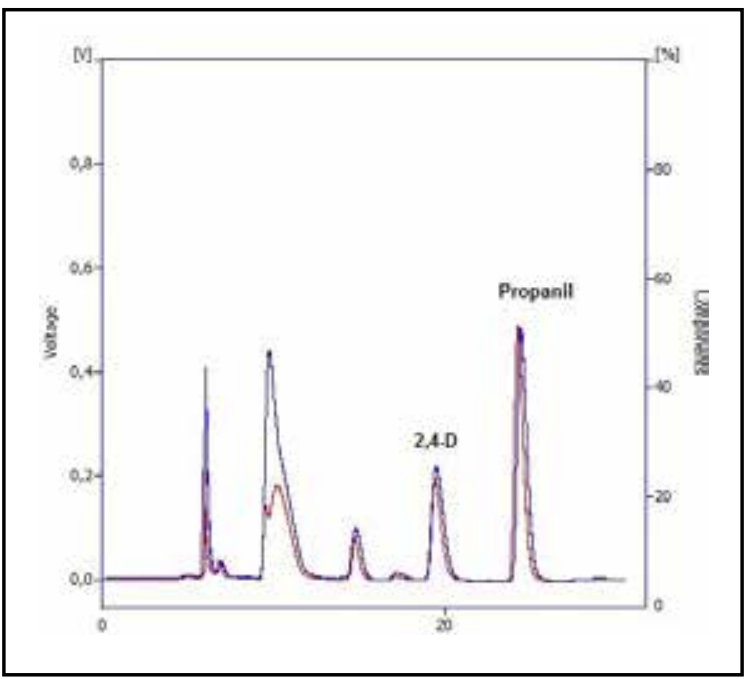

Figura 3 - Cromatogramas sobrepostos referente à primeira extração (dia zero) do controle e tratamento na maior concentração dos pesticidas $\left(0,1612 \mathrm{~g} \mathrm{Kg}^{-1}+0,072 \mathrm{~g} \mathrm{Kg}^{-1}\right.$ de Aminol e Herbipropanin respectivamente)

O procedimento de extração conseguiu, inclusive, extrair o metabólito 3,4-dicloroanilina (3,4-DCA) que já estava presente devido à decomposição do propanil (Figura 4). A confirmação deste composto foi feita mediante a comparação da análise do seu padrão nas mesmas condições cromatográficas. A Figura 4 evidencia que o 3,4-DCA esteve presente desde o início do estudo, porém, ressalta-se que em 20 dias de experimento ele manteve estável sua concentração na amostra do tratamento com a planta, diferente do que aconteceu com a amostra do controle, evidenciando assim, a capacidade da planta de fitorremediar esse metabolito.

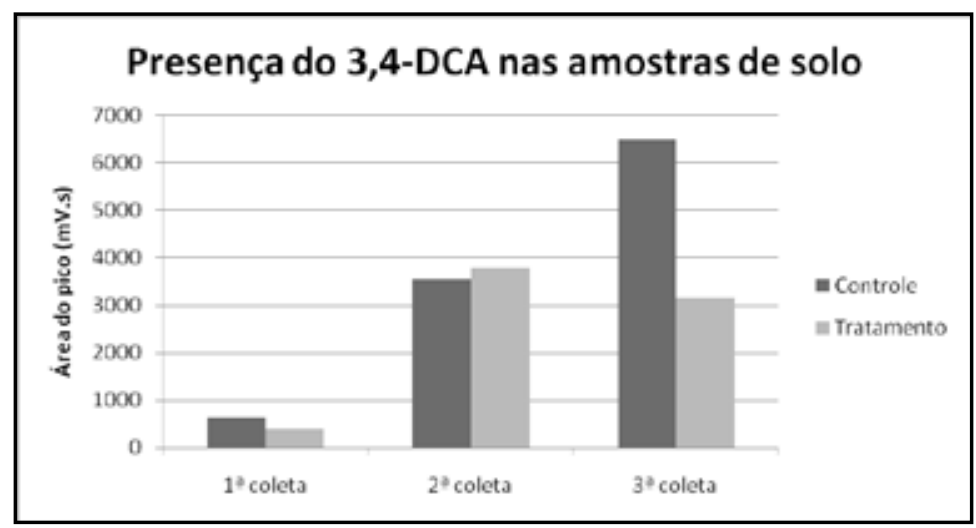

Figura 4 - Gráfico apresentando a capacidade da planta para a fitorremediação do composto 3,4-DCA (metabólito do propanil) que estava presente tanto nas amostras do tratamento quanto nas do controle durante as três coletas realizadas. Esses dados são referentes às amostras do tratamento e controle da concentração intermediária $\left(0,0806 \mathrm{~g} \mathrm{Kg}^{-1}+0,036 \mathrm{~g} \mathrm{Kg}{ }^{-1}\right.$ de Aminol e de Herbipropanin respectivamente) e mostram que a amostra com a planta foi capaz de estabilizar $50 \%$ deste metabólito. 
Os resultados da segunda coleta $\left(10^{\circ}\right.$ dia - Figura 5) mostraram que ocorreu uma autodegradação para o composto 2,4-D uma vez que tanto na amostra controle quanto na amostra do tratamento houve uma diminuição acentuada deste composto. Porém, o interessante nos resultados desta segunda coleta foi que o composto propanil já estava ausente na amostra do tratamento e ainda presente na amostra controle. Este resultado evidencia a fitorremediação pela Melissa officinalis para o composto propanil neste curto período de tempo. Esses resultados mostram que essas concentrações de propanil permanecem no solo da amostra controle por, pelo menos, 10 dias. Tal fato é confirmado de acordo com Primel e colaboradores (2007) que demonstram a detecção desse composto até 10 dias após aplicação do mesmo em lavouras de arroz.

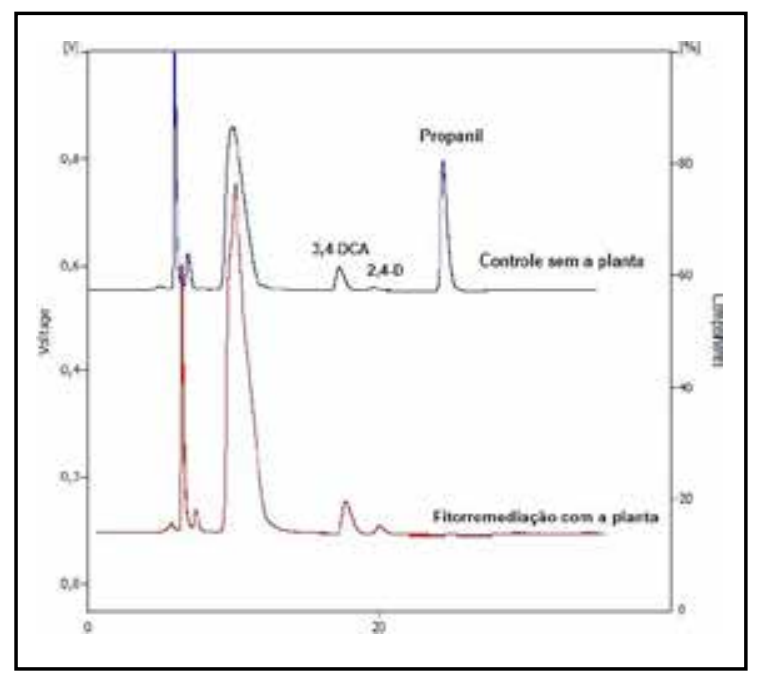

Figura 5 - Cromatogramas sobrepostos referentes à segunda extração (10º dia) com a amostra do controle e tratamento na maior concentração dos pesticidas $\left(0,1612 \mathrm{~g} \mathrm{Kg}^{-1}+0,072 \mathrm{~g} \mathrm{Kg}^{-1}\right.$ de Aminol e de Herbipropanin respectivamente). Essa figura evidencia a capacidade de fitorremediação da planta pelo composto propanil (Herbipropanin) em apenas 10 dias

Os resultados da terceira coleta $\left(20^{\circ}\right.$ dia - Figura 6) mostram ainda a presença do herbicida 2,4-D na amostra controle. Outros estudos relatam que este composto tem um tempo de meia-vida relativamente baixo em solo que variam de 6,4 dias em solos minerais e 8,3 dias em solos orgânicos e que sob circunstâncias normais, os resíduos de 2,4-D não são persistentes

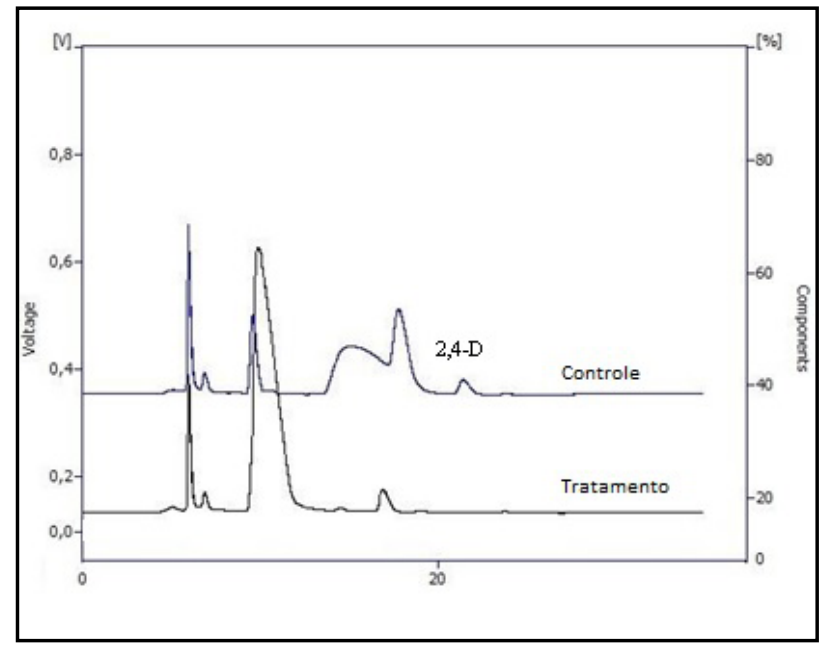

Figura 6 - Cromatogramas sobrepostos referentes à terceira extração (20ำ dia) com a amostra do controle e tratamento na maior concentração dos pesticidas $\left(0,1612 \mathrm{~g} \mathrm{Kg}^{-1}+0,072 \mathrm{~g} \mathrm{Kg}^{-1}\right)$. Na figura observa-se capacidade de fitorremediação da planta pelo composto 2,4-D (Aminol) em 20 dias de experimento

no solo, na água, ou na vegetação (2,4-D: FACT SHEET, 2000 apud Junior et al., 2002). Tais dados da literatura diferem dos resultados desse trabalho, no qual as amostras no $20^{\circ}$ dia ainda apresentarem este herbicida, o que provavelmente é justificado pelo tipo de solo utilizado neste experimento que deve diferir daqueles relatados pela literatura. Além disso, não podemos descartar o fato do experimento deste estudo ter sido realizado em ambiente fechado (em estufa), tendo como fatores relevantes a diferença da microbiota associada presente, capacidade de lixiviação e escoamento superficial da água, a intensidade da luz solar e dos ventos. Porém, observa-se que o 2,4-D não estava mais presente na amostra do tratamento, indicando a fitorremediação pela planta. 
$\mathrm{Na}$ ausência destes herbicidas e de seus metabólitos nos chás da planta, torna-se possível o cultivo da mesma para remediar o solo e um destino final a ela, com seu uso posterior como fonte de renda complementar. Estudos para aprimoramento podem ser realizados buscando conhecer o(s) mecanismo(s) que ocorrem na remediação por esta planta, além do estudo com diferentes tipos de solo, de outros pesticidas e de outros compostos orgânicos também poderão contribuir com os resultados deste estudo.

\section{Conclusões}

Este trabalho mostrou que a cultura de Melissa officinalis pode ser uma estratégia rápida, eficaz e de baixo custo para a fitorremediação de solos contaminados pelos herbicidas comerciais do 2,4-D e propanil em um apenas 20 dias de cultivo. Além disso, a planta mostrou ser promissora na fitorremediação do principal metabólito do propanil, o 3,4-DCA, que possui toxicidade maior que o propanil. A planta do estudo suporta elevadas concentrações destes dois herbicidas, muito superior ao recomendado para uso no cultivo de diferentes culturas. Essa característica permite que a Melissa Officinalis possa ser utilizada em casos de desastres ambientais para compostos orgânicos com estruturas semelhantes a estes pesticidas.

\section{Agradecimentos}

Os autores do trabalho agradecem a Universidade Federal do Pampa (UNIPAMPA) e a Fapergs/ARD nº 003-2012 pelo suporte e, à empresa Adama pela doação dos pesticidas comerciais.

\section{Referências}

2,4-D: FACT SHEET, 2000 Disponível em: http://www.gn.apc.orglpesticidestrustlaifacts/24d.htminJUNIOR, O. P. A.; SANTOS, T. C. R.; BRITO, N. M.; RIBEIRO, M. L. Revisão das Propriedades, Usos e Legislação do Ácido 2,4-diclorofenoxiacético (2,4-d). Cad: Pesq.São Luís, v. 13, n. 1, p. 60-70, 2002.

ANVISA. ANVISA - Monografias de Agrotóxicos: ANVISA. 2003.

BLANCO, M. C. S. G. et al. Cultivo de plantas aromáticas e medicinais. Boletim Técnico 247. Campinas-SP, 2007.

HARRIS, D. C. Análise Química Quantitativa: LTC. Rio de Janeiro, 2012.

JUNIOR, O. P. A.; SANTOS, T. C. R.; BRITO, N. M.; RIBEIRO, M. L. Revisão das Propriedades, Usos e Legislação do Ácido 2,4-diclorofenoxiacético (2,4-d). Cad: Pesq.São Luís, v. 13, n. 1, p. 60-70, 2002.

MADALÃO, J. A.; PIRES, F. R.; FILHO, A. C.;NASCIMENTO, A. F.; CHAGAS, K; ARAÚJO5, R. S.; PROCÓPIO,S. O.; BONOMO,R. Susceptibilidade de Espécies de Plantas com Potencial de Fitorremediação do Herbicida Sulfentrazone. Ceres. v. 60, n.1, p. 111-12. Viçosa, 2013.

NIELL, S.; PAREJA, L.; ASTEGGIANTE, L. G.; ROEHRS, R.; PIZZUTTI, I. R.; C.; G.; HEINZEN, H.; CESIO, M. V. Development of Methods for Multiresidue Analisys of Rice Post-Emergence Herbicides in Loam Soil and Their Possible Applications to Soils of Different Composition. Journalof AOAC International.v.93, p.425-431, 2010.

PRIMEL, E. G.; ZANELLA, R.; KURZ, M. H. S.; GONÇALVES, F. F.; MARTINS, M. L.; MACHADO, L. O. S.; MARCHESAN, E. Risk Assessment of Surface Water Contamination by Herbicide Residues: Monitoring of Propanil Degradation in Irrigated Rice Field Waters Using HPLC-UV and Confirmation by GC-MS. J. Braz. Chem. Soc. v.18, p.585, 2007.

ROSA, A. S. Fitorremediação de Pesticidas Utilizados em Lavouras de Arroz Através do Cultivo Hidropônico de Alface (Lactuca sativa L.). Dissertação (Mestrado em Bioquímica. Universidade Federal do Pampa. Uruguaiana, 2013.

RIBANI, M.; BOTTOLI, C. B. G.; COLLINS, C. H.; JARDIM, I. C. S. F.; MELO, L. F. C. Validação em Métodos Cromatográficos e Eletroforéticos. Química Nova. v.27, p.771-780, 2004. 
SBANO, A.; FERREIRA, J. V. R.; PECKLE, B. A. ; MACRAE, A.; DIREITO, I. C. N. Otimização de Método Cromatográfico para Quantificação do Herbicida Ácido 2,4-Diclorofenoxiacético (2,4-d). Acta Scientiae \& Technicae. Rio de Janeiro, v.1, n. 2, p 37-46, dec 2013.

SILVA, C.L.; FOLONI, L.L.; PARAÍBA, L. C.; PLESE, L. P. M. Previsão Ambiental da Distribuição dos Pesticidas Aplicados na Cultura do Arroz. Ecotoxicologia e Meio Ambiente. v. 17, p. 75-86, 2007.

SPADOTTO, C. A.; GOMES, M. A. F.; LUCHINI, L. C.; ANDRÉA, M. M. Monitoramento do risco ambiental de agrotóxicos: Princípios e recomendações. Documentos Embrapa Meio Ambiente. Jaguariúna-SP, 2004.

TOMLIN, C.D.S. (2007). A world compendium: the e-Pesticide Manual, 14th ed. CDROM version 4.0, The British Crop Protection Councill, Farnham, UK. ISBN 1-901396-42-8. 